\title{
USO DA BIOMANTA: MÉTODO DE SUBSTITUIÇÃO DE DRENAGEM SUPERFICIAL ATRAVÉS DA BIOENGENHARIA
}

\section{ARTIGO DE REVISÃO}

BORGES, Airton Pereira ${ }^{1}$, SILVA, Ana Thaisa Luz Vieira da²

BORGES, Airton Pereira. SILVA, Ana Thaisa Luz Vieira da. Uso da biomanta: Método de substituição de drenagem superficial através da bioengenharia. Revista Científica Multidisciplinar Núcleo do Conhecimento. Ano 05, Ed. 11, Vol. 25, pp. 105-116. Novembro de 2020. ISSN: 2448-0959, Link de acesso: https://www.nucleodoconhecimento.com.br/engenharia-civil/atraves-da-

bioengenharia, DOI: 10.32749/nucleodoconhecimento.com.br/engenhariacivil/atraves-da-bioengenharia

\section{RESUMO}

Programas de recuperação e proteção de áreas que foram impactadas ambientalmente pela erosão do solo são implementados para corrigir ou prevenir os danos causados, porém nem sempre são adotados métodos sustentáveis. Através do processo governado por agentes climáticos e a intervenção do homem, a erosão têm causado consequências que provocam investigações e debates acerca do assunto, principalmente em âmbito acadêmico e relacionado à bioengenharia. $O$ presente trabalho tem como objetivo dissertar e apresentar de forma documental a temática biomanta, um método com menor impacto ambiental e monetariamente viável. Composta por fibra de coco e polipropileno, a biomanta como uma opção para a substituição de drenagens superficiais, proporciona proteção imediata contra o efeito dos agentes erosivos, conservando a umidade do solo e, consequentemente, trazendo inúmeros benefícios como a proteção da vegetação.

\footnotetext{
${ }^{1}$ Pós-Graduado em Engenharia de Segurança do Trabalho e Graduado em Engenharia Civil.

${ }^{2}$ Graduada em Engenharia Civil.
}

RC: 67084

Disponível em: https://www.nucleodoconhecimento.com.br/engenharia-civil/atraves- 
Palavras-chaves: Bioengenharia, biomanta, erosão, vegetação.

\section{INTRODUÇÃO}

Os impactos do solo e do meio-ambiente em geral, preocupam e podem ser altamente perigosos, podendo causar malefícios irreparáveis para a natureza e a qualidade da vida humana. Por ser tratar de uma problemática cada vez mais discutida mundialmente em espaço acadêmico, científico e social, uma vez que apresenta grandes prejuízos decorrentes da ocupação desenfreada de áreas consideradas frágeis, o ambientalismo passa a ser associado com a engenharia através de técnicas que possibilitem a utilização de materiais e elementos como alternativa para mitigar e evitar esses impactos.

A perda desse recurso importante, o solo, através de processos de degradação como a erosão, pode causar a anulação da produção de alimentos, diminuição da qualidade da água e a destruição de ecossistemas. Muitas erosões poderiam ser evitadas se não houvesse o aumento de construção de casas e estradas muito próximas a praias, terrenos com altas declividades e áreas que o solo pode ter sido alterado ou que não apresenta mais suas características, como a remoção da vegetação de dunas e da destruição de recifes de corais, que agem como barreiras protetoras, o que poderia ter sido realizado com um planejamento dos projetos costeiros.

Os processo erosivos são fenômenos naturais que fazem parte da dinâmica terrestre de modelamento do relevo, a maior preocupação em relação a eles é sua intensificação, associados a práticas agrícolas e ocupações urbanas inadequadas, que geram diversos prejuízos econômicos e ecológicos (CAROLINA, 2016).

A restauração ou proteção de áreas degradadas ou que tenham risco consiste em criar condições favoráveis para o seu desenvolvimento utilizando funções ecológicas, facilitando e acelerando o processo através de ciclagem de nutrientes,

RC: 67084

Disponível em: https://www.nucleodoconhecimento.com.br/engenharia-civil/atraves- 
promovendo o acúmulo de biomassa, processo que deve ser realizado com o manejo do solo, para o restabelecimento da vegetação e retorno da biota. Diferentes métodos são utilizados para reduzir a erosão do solo, implicando na conservação e manutenção de uma cobertura vegetal, uma alternativa sustentável é o emprego da bioengenharia nesse processo.

Também conhecida como biotécnica ou engenharia natural, a bioengenharia é um processo eficiente para facilitação da sucessão natural em áreas degradadas, valendo-se de técnicas biológicas, nas quais plantas ou outros elementos naturais são usados como material vivo para o desenvolvimento de estruturas que propiciem os efeitos desejados e substituem elementos que agridem a natureza (ROBSON, 2011).

As abordagens da bioengenharia tem como principal vertente, priorizar o uso de materiais disponíveis no local e diminuir o impacto ambiental, portanto, se torna uma alternativa mais acessível e ecológica. Com o avanço desses estudos e técnicas para recuperação e conservação, popularizou-se em diversos países como Áustria, Alemanha, China, Estados Unidos, França, Itália e Suíça, principalmente na contenção de encostas e taludes, continuando o aperfeiçoamento desse método sustentável, o que nos leva a considerar os métodos das biomanta para tais finalidades.

\section{OBJETIVO}

Considerando que técnicas de bioengenharia não são muito divulgadas e utilizadas no Brasil, o objetivo deste trabalho foi realizar uma revisão bibliográfica a respeito da bioengenharia de solos, visando auxiliar futuras pesquisas e a incentivar seu uso na recuperação de áreas degradadas. A pesquisa deste estudo foi realizada de maneira documental, através de análise de artigos, publicações, livros e relatórios sobre o referente tema.

RC: 67084

Disponível em: https://www.nucleodoconhecimento.com.br/engenharia-civil/atraves- 
- Apresentar materiais da composição da biomanta;

- Dissertar sobre proteção e recuperação dos solos com biomanta.

\section{REFERENCIAL TEÓRICO}

\subsection{EROSÃO}

A Erosão é um processo de desgaste, transporte e sedimentação das partículas de solo, dos subsolos e das rochas, resultantes da ação dos agentes erosivos: a água, os ventos e os seres vivos. O processo de desagregação das partículas das rochas, denominados como sedimentos, é ocasionado pela ação da meteorização, um conjunto de processos químicos, físicos e biológicos que causam o desgaste dos solos e das rochas, aquele que deve ser evitado para que não haja propagação da erosão. Assim, o deslocamento desses sedimentos realiza-se pela ação da gravidade e dos elementos da superfície.

O processo desenfreado de erosão traz inúmeros prejuízos para o meio ambiente, já que atua no desgaste do solo, atrapalha a continuação de espécies de vegetais e animais, além de prejudicar a atividade humana.

Existem várias formas de se classificar e dividir as erosões, diversificando-as de acordo com a sua velocidade, esfera de influência, agente causador ou a sua localidade geográfica.

A erosão geológica trata de um processo lento e gradativo que constrói diversas formas e relevos existentes como, por exemplo, a formação de vales, caminhos pelos quais os rios passam. Enquanto a erosão acelerada envolve, na maioria das vezes, as atividades humanas que comumente resultam na rápida destruição ou danificação dos solos.

\section{i. Erosão fluvial}

RC: 67084

Disponível em: https://www.nucleodoconhecimento.com.br/engenharia-civil/atraves- 
É provocada pela ação das águas dos rios sobre as superfícies dos cursos d'água e de encostas, transformando o seu curso em vales mais profundos que seu entorno. Operam no desgaste do solo durante enchentes periódicas ou períodos de cheias. É fortalecida com a retirada das matas ciliares, ou seja, as vegetações localizadas nas margens dos rios.

\section{ii. Erosão gravitacional}

Fundamenta-se na ruptura, no transporte e na deposição de sedimentos da superfície, em virtude da ação da gravidade, com a queda de partículas e rochas. Acontece, principalmente, em regiões montanhosas e com alta declividade

\section{iii. Erosão marinha}

Ocasionada pelas águas dos mares e oceanos, opera na modelagem da morfologia litorânea, cooperando na formação de praias e de paisagens costeiras como, por exemplo, as falésias.

\section{iv. Erosão eólica}

É motivada pelas ações dos ventos sobre a superfície, provocando a meteorização das rochas, no transporte de sedimentos e partículas menores, degradando morosamente formações rochosas, de modo a lhes conferir formas peculiares. Costuma ser um processo mais lento por não haver interferência da água

\section{v. Erosão glacial}

Sobrevém dos congelamentos dos solos decorrente das suas movimentações em blocos e abruptos (como as avalanches). Também atua no congelamento das águas que se dilatam e provocam alterações na composição e disposição das rochas e dos solos, transportando os sedimentos.

RC: 67084

Disponível em: https://www.nucleodoconhecimento.com.br/engenharia-civil/atraves- 


\section{vi. Erosão pluvial}

Ocorre em razão da ação das águas das chuvas, que desgastam a superfície e transportam sedimentos, em menores quantidades, apenas provocando a lavagens dos solos e em maiores intensidades e em solos sem vegetação (principalmente em áreas inclinadas), erosões mais profundas.

\subsection{BIOMANTAS}

A biomanta, também conhecida como telas vegetais, é um biotêxtil translúcido flexível, composta de fibras vegetais desidratadas que são entrelaçadas por meio de costuras longitudinais, se assemelhando a esteiras de fios resistentes, látex natural, colas, grelhas de polipropileno e outras substâncias e baixa higroscopicidade.

A biomanta dispõe de alta resistência e é enrolada em bobina e embalada por filme plástico, na qual proporciona proteção imediata contra o efeito dos agentes erosivos, processos de deslocamento e mobilização de partículas em áreas recémterraplanadas, áreas de disposição de resíduos industriais, aterros sanitários, margens de rios, canais de taludes, ferrovias, rodovias e/ou quaisquer superfícies de solo desprotegidas contra a ação dos processos erosivos, conservando assim, a umidade do solo por mais tempo, o que concede circunstâncias mais apropriadas de germinação e desenvolvimento das espécies vegetais semeadas, além de prover nutrientes e servir de fonte de matéria orgânica para o solo, favorecendo a sua estruturação.

$\mathrm{RC}: 67084$

Disponível em: https://www.nucleodoconhecimento.com.br/engenharia-civil/atraves- 


\section{DESENVOLVIMENTO}

\subsection{COMPOSIÇÃO QUÍMICA E BIOLÓGICA DAS BIOMANTAS}

Material geotêxtil, composto basicamente por polipropileno e fibra de coco, tem como objetivo principal, na visão sustentável, mitigar grandes distúrbios ambientais, podendo ser compostas também por fibras vegetais, sintéticas e palha agrícola.

Figura 1: Composição da Biomanta

\begin{tabular}{|c|c|}
\hline caption & nt 67089" \\
\hline Matriz orgânica & $\begin{array}{l}100 \% \text { fibra de } \\
\text { coco }\end{array}$ \\
\hline Comprimento (m) & 25,00 \\
\hline Largura (m) & 2,00 \\
\hline Área da bobina $\left(\mathrm{m}^{2}\right)$ & 50,00 \\
\hline $\begin{array}{l}\text { Gramatura da matriz } \\
\text { orgânica }\left(\mathrm{g} / \mathrm{m}^{2}\right)\end{array}$ & 400,00 \\
\hline Peso da bobina $(\mathrm{kg})$ & 75,00 \\
\hline Longevidade (meses) & Permanente \\
\hline $\begin{array}{l}\text { Resistência à tração } \\
(\mathrm{kn} / \mathrm{m})\end{array}$ & 3,40 \\
\hline Diâmetro da bobina (m) & 0,80 \\
\hline $\begin{array}{l}\text { Inclinação máxima do } \\
\text { talude }(V: H)\end{array}$ & $>4: 1$ \\
\hline Suscetibilidade à Erosão & Alta \\
\hline
\end{tabular}

$$
\text { align="aligncenter" width="741"] }
$$



Fonte: Deflor Bioengenharia (2007)[/caption]

\subsubsection{FIBRA DE COCO}

Originada do coqueiro, a fibra de coco surge do seu fruto, que é uma importante matéria-prima tanto para o setor alimentício como para fabricação de outros produtos. A água do coco é tema de estudo de diversas pesquisas nas áreas da

RC: 67084

Disponível em: https://www.nucleodoconhecimento.com.br/engenharia-civil/atravesda-bioengenharia 
medicina e da biotecnologia, porém o aproveitamento desse fruto vai além, em razão do interesse pela parte externa, especialmente pela fibra presente na casca.

A estrutura do coco consiste num interior oco, onde o albúmen líquido (água) se encontra, transformando-se de modo progressivo em um albúmen sólido. Este é envolvido por uma sapucaia, o endocarpo (parte mais dura), sucedendo o mesocarpo (casca) que compõe a maior parte do fruto, e por fim, um fino exocarpo de cor verde, amarela ou marrom (ARAGÃO, 2002).

A fibra de coco verde é composta de celulose, hemicelulose e pectina, componentes que funcionam como indutores na produção de enzimas extracelulares, como as celulases, xilanases, pectinases e outras, sendo adequada para o desenvolvimento microbiano sem que haja necessidade de grandes complementações nutricionais (SENHORAS, 2004).

Após o consumo do líquido do coco, a casca pode ser reaproveitada, extraindo suas fibras, que são costuradas industrialmente, formando uma trama resistente protegidas por redes de polipropileno, o que permite sua degradabilidade.

\subsubsection{POLIPROPILENO}

Por ser um material produzido a partir da polimerização do gás propileno ou propeno, ele pode ser reciclado com certa facilidade, sendo um dos plásticos mais utilizados na engenharia, principalmente devido sua versatilidade e reutilização sem perder suas propriedades. Apresenta características importantes como baixo custo, resistência química e resistência à flexão.

\subsection{MÉTODO DA BIOMANTA}

De acordo com Juliana e João (2018), o método da biomanta possui facilidade executiva, evitando o carregamento das sementes pela ocorrência das precipitações

RC: 67084

Disponível em: https://www.nucleodoconhecimento.com.br/engenharia-civil/atraves- 
pluviométricas, pois as sementes estão sob a manta, com isso previne-se a dormência das sementes. Porém, tal ação depende das condições climáticas e demanda manutenções.

\subsection{RECUPERAÇÃO DE ÁREAS DANIFICADAS COM BIOMANTA}

Áreas danificadas são as que possuem um ecossistema transformado ou degradado parcialmente ou inteiramente pela ação humana, sendo este o responsável recuperação das mesmas, de acordo com a Lei $n^{\circ}$ 9.985, de 18 de julho de 2000 (BRASIL, 2000).

Conveniente da ação humana em atividades de mineração, disposição inadequada de resíduos e desmatamento, as áreas danificadas apresentam processos erosivos, diminuição e ausência de proteção vegetal e confronto no restabelecimento de um equilíbrio regulado.

Avaliando o grau dos danos da área, é possível utilizar técnicas de recuperação que possibilitam sua regeneração e que deve prever a sua nova aplicação em concordância com um propósito de uso do solo predeterminado, tal propósito deve ter como fundamentos o uso sustentável dos recursos naturais e a preservação dos ecossistemas como diretrizes, fazendo com que a área danificada volte a contar com os recursos abióticos e bióticos suficientes para se manter em equilíbrio.

Conforme o grau de degradação, o local pode sofrer uma restauração, planejando o retorno a um estado considerado estável. A área em questão também pode necessitar de uma reabilitação, na qual sofrerá um retorno até o estado intermediário das condições vegetativas. Em conclusão, poderá sofrer uma redefinição quando se faz necessário a presença humana para auxiliar o processo de restauração.

Encontrando o local, tipo de ecossistema, o agente causador da degradação pode promover o processo de recuperação da área, verificando também se há

$\mathrm{RC}: 67084$

Disponível em: https://www.nucleodoconhecimento.com.br/engenharia-civil/atraves- 
necessidade de intervenções indiretas e assim empregando a técnica específica de acordo com as condições da área danificada.

\subsubsection{PLANTIO POR SEMENTES}

O plantio por sementes é uma técnica de regeneração e para que seja bem realizada se faz necessário que seja aplicada condições mínimas que permitam o processo de restauração, privilegiando o recrutamento de embriões vegetais e concedendo a substituição de simbiontes e polinizadores faltantes.

\subsubsection{CONDIÇÃO DA REGENERAÇÃO NATURAL}

Conforme o nível de danos na área é possível que a mesma se regenere naturalmente, no entanto, para que isso aconteça se faz necessário transpor barreiras que possam prejudicar esse processo, tais como: falhas no desenvolvimento de mudas jovens, ausência de sementes para a colonização local, falta de simbiontes, polinizadores, dispersores e entre outros. Este método vem sendo extensivamente indicado nos casos de reabilitação de áreas de preservação permanente.

\subsubsection{PLANTIO DE MUDAS}

O plantio de mudas é uma das técnicas menos aplicada por motivos monetários, no entanto, é uma das mais efetivas para a reabilitação de uma área degradada. O plantio de mudas nativas, geralmente, manifesta alto índice de crescimento e após 2 anos, geralmente a área já se encontra retomada e em equilíbrio.

\subsection{APLICAÇÃO DA BIOMANTA}

De acordo com Naresi (2015), as biomantas vem acondicionadas em bobinas. A aplicação da biomanta deve ser iniciada pelo topo do talude, desenrolando-a até a

RC: 67084

Disponível em: https://www.nucleodoconhecimento.com.br/engenharia-civil/atravesda-bioengenharia 
bobina, fixando-a e moldando-a, posteriomenete, sobre uma valeta escavada com $10 \mathrm{~cm}$ de largura e $10 \mathrm{~cm}$ de profundidade, permitindo que ela ultrapasse $20 \mathrm{~cm}$ além da valeta.

A utilização das biomantas em obras de engenharia tem a finalidade de substituir os dispositivos tradicionais de drenagens superficiais.

\subsubsection{METODOLOGIA EXECUTIVA SIMPLIFICADA}

Tabela 1: Ordem de execução

\begin{tabular}{r|l}
1 & Ancoragem superior \\
\hline 2 & Preenchimento de erosões com retentores de sedimentos tipo Bermalonga \\
\hline 3 & Construções de bermas artificiais \\
\hline 4 & Preparo do solo (coveamento e semeio) \\
\hline 5 & Ancoragem inferior \\
\hline 6 & Grampeamento longitudinal \\
\hline 7 & Grampeamento transversal \\
\hline 8 & Efeitos da vegetação na estabilidade de taludes
\end{tabular}

Fonte: Deflor Bioengenharia (2014).

RC: 67084

Disponível em: https://www.nucleodoconhecimento.com.br/engenharia-civil/atraves- 
Figura 2: Metodologia Simplificada

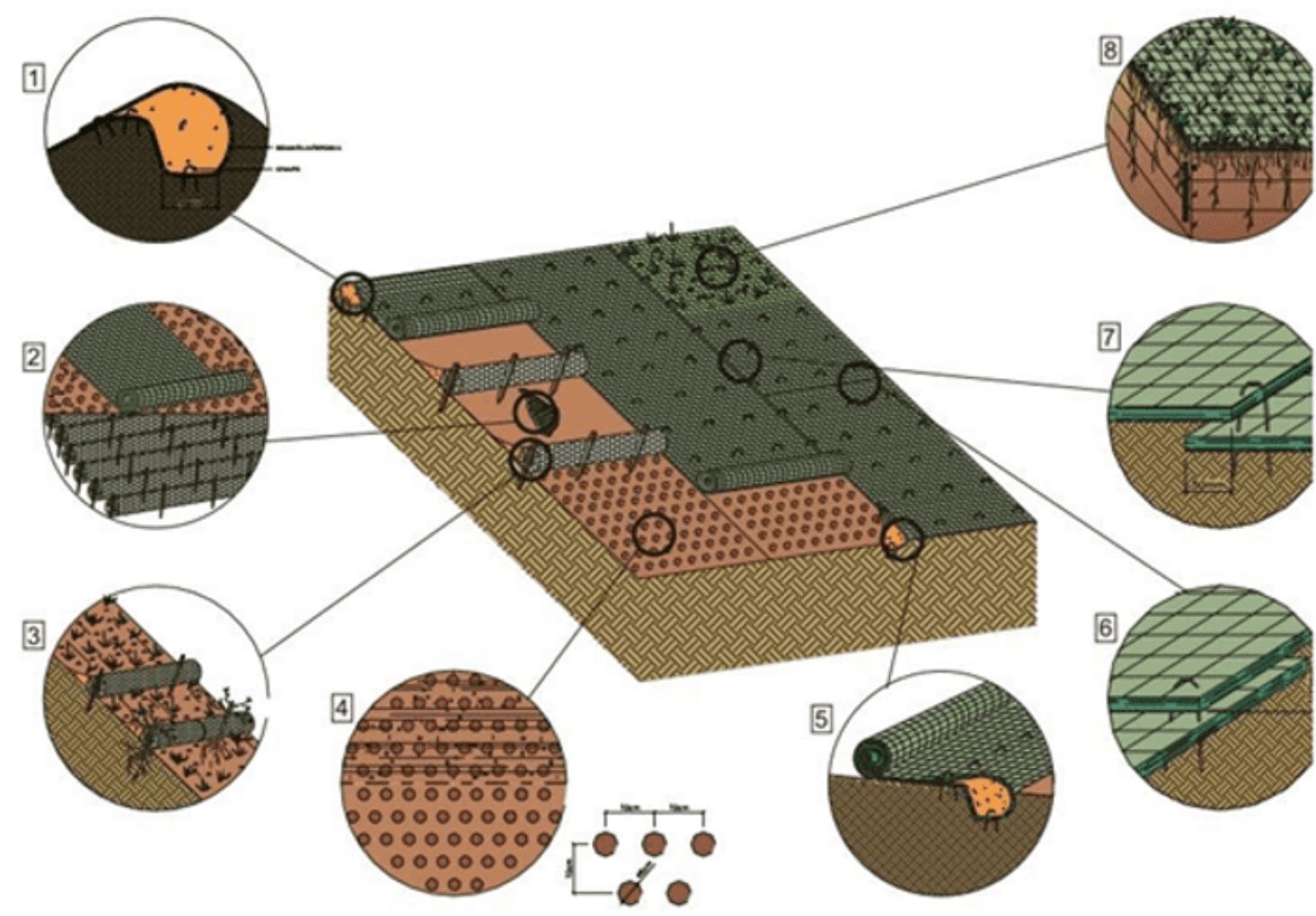

Fonte: Deflor Bioengenharia (2014).

\section{CONSIDERAÇÕES FINAIS}

Neste estudo observamos o quanto é importante ter conhecimento a respeito dos problemas referentes às erosões provenientes das grandes áreas danificadas pelo Brasil, para ser indicado e utilizado métodos para a recuperação, contenção e tratamento das mesmas.

Observamos que a bioengenharia, em acordo a outras atividades pluridisciplinares, através da biomanta, vem mostrando resultados convenientes e monetariamente viáveis nesta área.

RC: 67084

Disponível em: https://www.nucleodoconhecimento.com.br/engenharia-civil/atravesda-bioengenharia 
No objetivo de ampliar o estudo e o conhecimento, evidenciamos que a aplicação do tratamento vegetativo e da reabilitação das áreas danificadas de forma correta, não só conduz de maneira eficiente a solução do problema como também agrega de maneira ecológica.

\section{REFERÊNCIAS}

ANTONIO, A. M. Mestrado acadêmico em bioengenharia EESC 1980 a 2012: Avaliação dos egressos. 2014. 157 p. Trabalho de Conclusão de Curso (Título de Doutor em Ciências) - Programa de Pós-Graduação Interunidades Bioengenharia de São Carlos/ Faculdade de Medicina de Ribeirão Preto/ Instituto de Química de São Carlos da Universidade de São Paulo, São Carlos, 2014.

BRAS VERDE MG. Biomanta vegetal e seu papel na estabilização de solos. Disponível em: <http://www.brasverdemg.com.br/post/biomanta-vegetal-e-seu-papelna-estabiliza\%C3\%A7\%C3\%A3o-de-solos> Acesso em: 07 set. 2020.

BRASIL. Lei n. 9.985, de 18 de jul de 2000. Recuperação de áreas degradadas. Brasil, 3 p, jul. 2000. Constituição Federal.

BRAUN, M. G. Técnica de bioengenharia de solos aplicada na remediação de áreas degradadas por erosão hídrica no Arroio Tamanduá em Marques de Souza. 2018. 114 p. Trabalho de Conclusão de Curso (Título de Bacharel em Engenharia Ambiental) - Universidade do Vale do Taquari, Lajeado, 2018.

CORRADINF, E. et. al. Composição química, propriedades mecânicas e térmicas da fibra de frutos de cultivares de coco verde. Revista Brasileira de Fruticultura, Jaboticabal, 2009.

COUTO, L. Técnicas de bioengenharia para revegetação de taludes no Brasil. Centro Brasileiro para Conservação da Natureza e Desenvolvimento Sustentável, Viçosa, 2010.

RC: 67084

Disponível em: https://www.nucleodoconhecimento.com.br/engenharia-civil/atraves- 
DEFLOR Bioengenharia. Guia de instalação de biomantas antierosivas, retentores de sedimentos e hidrossemeio. 2007. Disponível em: $<$ http://deflor.com.br/publicacoes-e-links/>. Acesso em: 14 set. 2020.

DISARZ, R. Desenvolvimento tecnológico em bioengenharia de solos aplicável em programas de restauração ecológica. Trabalho de Conclusão de Curso (Título de Mestre em Ciências Florestas Tropicais) - Instituto Nacional de Pesquisas da Amazônia, Manaus, 2011.72 p.

FIGUEIRÔA, A. J. T. Bioengenharia na estabilização de taludes: Avaliação experimental da aplicação de tapetes de grama e pó de coco. Trabalho de Conclusão de Curso (Título de Mestre em Engenharia Agrícola) - Universidade Federal Rural de Pernambuco, Recife, 2018. 64 p.

FILHO, R. N. A. Comportamento de talude da margem do rio São Francisco submetido à técnica de bioengenharia de solos. Trabalho de Conclusão de Curso (Título de Mestre em Agroecossistemas) - Universidade Federal de Sergipe, Sergipe, 2012. $136 \mathrm{p}$.

GRUPO RB E AJ Engenharia e Facilities. Você sabe o que são biomantas ou telas vegetais? Disponível em: <http://www.gruporbengenharia.com.br/vernoticias/voce-sabe-o-que-sao-biomantas-ou-telas-vegetais-/32> Acesso em: 05 set. 2020.

JULIAN, C. et. al. Áreas degradadas e contaminadas: Utilização de técnicas de bioengenharia para recuperação de focos erosivos em áreas degradadas por erosão hídrica no distrito de Amadeu Amaral, município de Marília - SP. XIV ENEEAmb, Brasília, 2016.

RC: 67084

Disponível em: https://www.nucleodoconhecimento.com.br/engenharia-civil/atraves- 
KOTIK, H. G. Natural fibers and composite materials reinforced with natural fibers: The motivation for their research and development. Revista Matéria, Rio de Janeiro, 2019.

LUCENA, L. Introdução à bioengenharia de solos. Revista CEIBE, Belo Horizonte, 2007.

NARESI. L. A. Recuperação de áreas degradadas: Estudo de caso nos taludes da Estrada de Ferro Carajás - Floresta Nacional de Carajás (FLONA). Trabalho de Conclusão de Curso (Título de Especialização em Analista Ambiental) Universidade Federal de Juiz de Fora, Juiz de Fora, 2015. 104 p.

NTC Brasil. Biomanta fibra de coco. Disponível em: <https://www.ntcbrasil.com.br/biomanta-fibra-de-coco/> Acesso em: 10 set. 2020.

RAMALHO C. L. Biomantas protegem de forma imediata os solos contra a ação de agentes erosivos. Disponível em: $<$ https://www.aecweb.com.br/emp/cont/m/biomantas-protegem-de-forma-imediataos-solos-contra-a-acao-de-agentes-erosivos_185_4341> Acesso em: 11 set. 2020.

SANTOS, F. E. et. al. A fibra de coco como matéria-prima para o desenvolvimento de produtos: uma prospecção tecnológica em bancos de patentes. Caderno de Prospecção, Salvador, 2019.

SCHMEIER, N. P. Bioengenharia de solos: Uma alternativa à recuperação de áreas degradadas. Revista destaques acadêmicos, Lajeado, 2013.

SILVA, J. C. G. Estudo comparativo entre técnica de proteção superficial de taludes situados na rodovia SP-563: Biomanta, hidrossemeadura e grama em placa. VII Simpósio Internacional de Gestão de Projetos, Inovação e Sustentabilidade, São Paulo, 2018.

RC: 67084

Disponível em: https://www.nucleodoconhecimento.com.br/engenharia-civil/atraves- 
SOLERA, M. L. et. al. Bioengenharia de solos: Aplicabilidade na recuperação de áreas mineradas e na oferta de serviços ambientais. Revista Brasileira de Ciências Ambientais, São Paulo, 2014.

TECNIGEO. Biomantas antierosivas. Disponível em: <http://tecnigeo.com.br/site/biomantas-antierosivas/> Acesso em: 10 set. 2020.

Enviado: Outubro, 2020.

Aprovado: Novembro, 2020.

$\mathrm{RC}: 67084$

Disponível em: https://www.nucleodoconhecimento.com.br/engenharia-civil/atravesda-bioengenharia 